\title{
Analysis of vibration influence on people in buildings in standards approach
}

\author{
J. Kawecki \& A. Kowalska \\ Cracow University of Technology, Poland
}

\begin{abstract}
People living in buildings may be exposed to dynamic action. Increasingly in the diagnosis and design of buildings there is a need to take into account these activities and verification of compliance of the building requirements for vibration comfort of people residing in buildings. This study presents the results of analysis of such criteria in the following standards: Polish PN-88/B-02170, British BS 6472-1, German DIN 4150 and ISO international standards. Based on the results of this analysis and on the review of selected items of literature application of standards recommendations in diagnosis and design of buildings, as well as areas for further research on this subject, were indicated.

Keywords: vibration, vibration impact on people in buildings, vibration comfort.
\end{abstract}

\section{Introduction}

In the vicinity of completed and designed buildings there occur different sources of vibration, which are called paraseismic action. They are transmitted through the subsoil to the foundations and basement walls of buildings and constitute their kinematic forcing. For this type of dynamic action vibrations induced by means of transport passages are included and they are called communication vibration. During the vibration of buildings inertia forces are also generated in addition, apart from static load to the construction. In the diagnosis and design of buildings these forces are taken into account by analyzing the structure satisfaction in the requirements for stiffness and strength. Exceeding these requirements may lead to acceleration of wear and even structural damage.

In areas of buildings there maybe people who are exposed to vibration and who having no direct influence on the source of vibration - perceive these 
vibrations in a passive way. Users of building space should be provided with the necessary requirements for vibration comfort.

Calculation methods and experimental studies are developed and they provide not only a reliable and objective evaluation of dynamic action on people in the buildings, but also prediction of these activities. An important element of such a procedure is the criteria used in assessing the problem, based on the results of many studies and developed verification criteria, which then are included in the standards documents. These criteria are regarded as requirements of an objective and considered opinion in dynamic diagnosis and building design.

This paper presents the results of the analysis stored in the standard procedures and criteria for assessing the influence of vibration on people in buildings. Provisions of the standards: Polish PN-88/B-02171 [1], British BS 6472-1 [2], German DIN 4150-2 [3] and ISO international standards [4, 5] were taken into account.

\section{Research on influence of vibrations on people}

For many years, research on the influence of vibrations on people was performed. To make a comparison of results of these tests possible, two body positions of vibration reception by people was determined by linking them with an orthogonal reference system.

A person in a sitting and standing position perceives vibration by the feet or seat surface in such a way that the axis " $z$ " which runs along the spine (axis line: foot - head) is a vertical axis and the axes of "xy" take the horizontal direction.

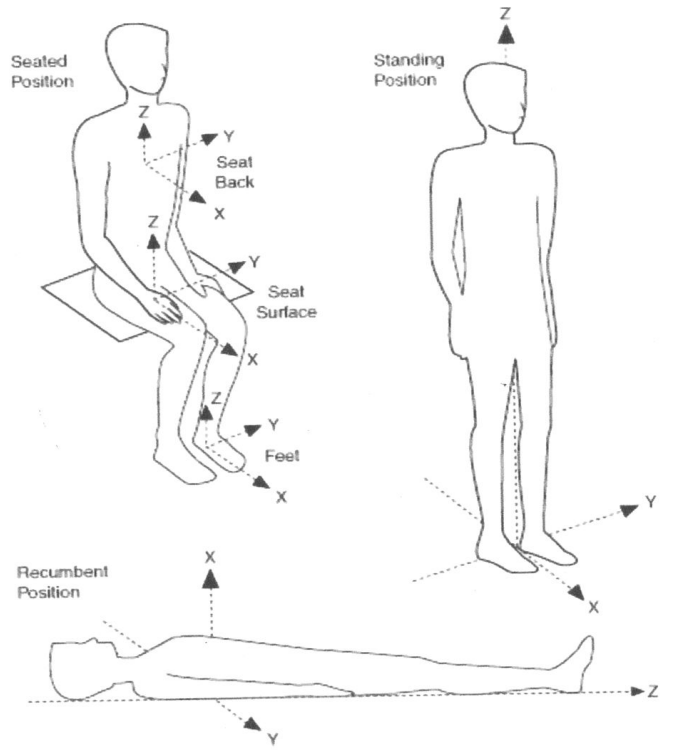

Figure 1: Directions of vibration reception by man. 
In the recumbent person the entire body surface perceives vibrations in such a way that the axis " $\mathrm{z}$ " is the horizontal axis. Axes $\mathrm{x}$ and y directions are marked: back - chest (axis " $x$ "), and side to side (axis " $y$ ").

Research on the influence of vibrations on man held in each of the two body positions was performed during many laboratory tests and is carried on (cf. the work of Tamura et al. [6] Blume [7], Benson et al. [8].) Verification of these results was carried out on real objects (cf. the work of Goto [9], Jeary et al. [10], Hansen et al. [11], Reed [12]). Efforts were undertaken to eliminate in this way the influence of individual perceptions of vibration. It shows from these and earlier studies showed that human response to vibration depends on many factors, of which the most significant influences are: frequency of vibration, amplitude of movement, direction and vibration conditions of acceptance.

The basic level of reference in assessing the influence of vibrations on people is called limit vibration sensation. The results in this regard were taken as the basis for formulation of criteria for assessing the influence of vibrations on people. If the vibrations at the place of receipt by people are characterized by values below sensation threshold of vibration, they can be considered as undetectable by man. In clinical and verification testing there is also obtained information about the parameters characterizing the vibrations, which still provide appropriate vibrational comfort for people. Vibration of parameters higher than described above are considered as infringing the conditions of necessary comfort for human to perform tasks the premises are designed for (e.g. office, residential, hospital, etc.).

\section{The methodology and assessment criteria}

The criteria used in assessing the influence of vibration on people in buildings depend on the evaluation method. There are three basic methods of assessment in which the following parameters are considered:

a) acceleration (velocity) of vibration corrected in the whole frequency range,

b) spectrum (frequency structure) of the effective value (RMS) of acceleration (velocity) of vibration in $1 / 3$ octave band,

c) vibration dose.

Corrected value (present in standards [1, 3]) is determined by measuring the vibration at the place of receipt by the person using the correction by means of a correction filter. Characteristics of the correction filter is described by the values of correction factors assigned to the center frequencies of $1 / 3$ octave bands. The measurement information is obtained, expressed by one number, which is compared with the corresponding value of providing the necessary vibrational comfort to people in the building. Application of the corrected value of vibration acceleration in the evaluation of their influence on people is relatively simple, but simultaneously deficient in information. In the case of infringement of requirements in the concerning provision of necessary comfort, to people in 
buildings no information is obtained from such studies about the frequency band in which the violation occurred. You cannot, therefore, on this basis determine at what frequency and at what degree reduction of vibration should be introduced to ensure people have the necessary vibration comfort. For these reasons, later in this study this evaluation parameter will not be analyzed.

More relevant information useful in assessing the influence of vibration on people is obtained on the basis of a presentation in the form of the frequency curve spectrum RMS acceleration in $1 / 3$ octave bands. This evaluation parameter is adopted in standards $[1,4,5]$. By comparing the frequency structure of the measured frequency curve with the corresponding frequency providing the necessary comfort of vibration to people in the building, not only is information about a possible breach of the requirements obtained, but also the frequency band in which the violation occurred.

The third of the applied parameters of the characteristics of vibration allows analyzing the effect of vibration on people in buildings by reference to the fulltime assessment of the impact of vibration. Introduction of a value defined as the vibrations dose for assessment of the influence of vibration on people, permits to refer the criteria adopted to assess vibrations of varying duration and repetition (continuous, intermittent, impulse). Their action is being considered during the entire period of human exposure to vibration. Vibration dose was introduced to assess the vibration in the standards $[2,3,5]$. In the standard [2] vibration dose denotes as VDV and expressed in $\left[\mathrm{m} / \mathrm{s}^{1,75}\right]$ is given by formula:

$$
V D V=\left(\int_{0}^{T} a^{4}(t) d t\right)^{0.25}
$$

where: a $(\mathrm{t})$ - acceleration $\left[\mathrm{m} / \mathrm{s}^{2}\right]$ as a function of time with the weightings $\mathrm{Wb}$ or $\mathrm{Wd}$ introduced depending on the vibration frequency and direction of its transmission to people, $\mathrm{T}$ - total time of vibration [s].

Depending on the type of vibration procedures for determining the vibration dose for the entire period of vibration effects (day -16 hours, night -8 hours) are also given in the said standards. For example, at vibration of a continuous character the dose of vibrations per the considered period of the day is determined by the formula:

$$
V D V_{D A Y}=\left(\frac{t_{d a y}}{t_{\tau}}\right)^{0,25} V D V_{\tau}
$$

where: $V D V_{\tau}$ - vibration dose determined in the representative time $\tau,\left[\mathrm{m} / \mathrm{s}^{1,75}\right]$, $t_{\text {day }}$ - duration time of the interval of the day in question (day, night), [s], $\mathrm{t}_{\tau}$ - total duration of vibration corresponding to the vibrations of the analyzed representative time $\tau[\mathrm{s}]$. 
In the standard [3], in turn, - denoting frequency curve $\mathrm{KB}(\mathrm{t})$ - values similar to those described in [2] are used in the assessment of vibration exposure. The nature of vibrations is also taken into account through introduction of the correction resulting from the relation of timing of the vibration (exposure to vibration) to the total time of the considered time of the day (day/night). The parameters of assessment of the influence of vibration on people in buildings are related to the assessment criteria.

The standards, which requirements are here compared to the requirements of the vibration assessment criteria are given in the frequency range vibration from 1 to $80 \mathrm{~Hz}$. The reference level is the sensation threshold of vibration, taking into account the different sensitivity of man to vibration, depending on the direction of transmission $(\mathrm{z}, \mathrm{xy})$.

Figure $2(a[1,4,5])$ shows the lines corresponding to the sensation threshold of vibration transmitted to people in the direction $\mathrm{z}$ and directions $\mathrm{xy}$.

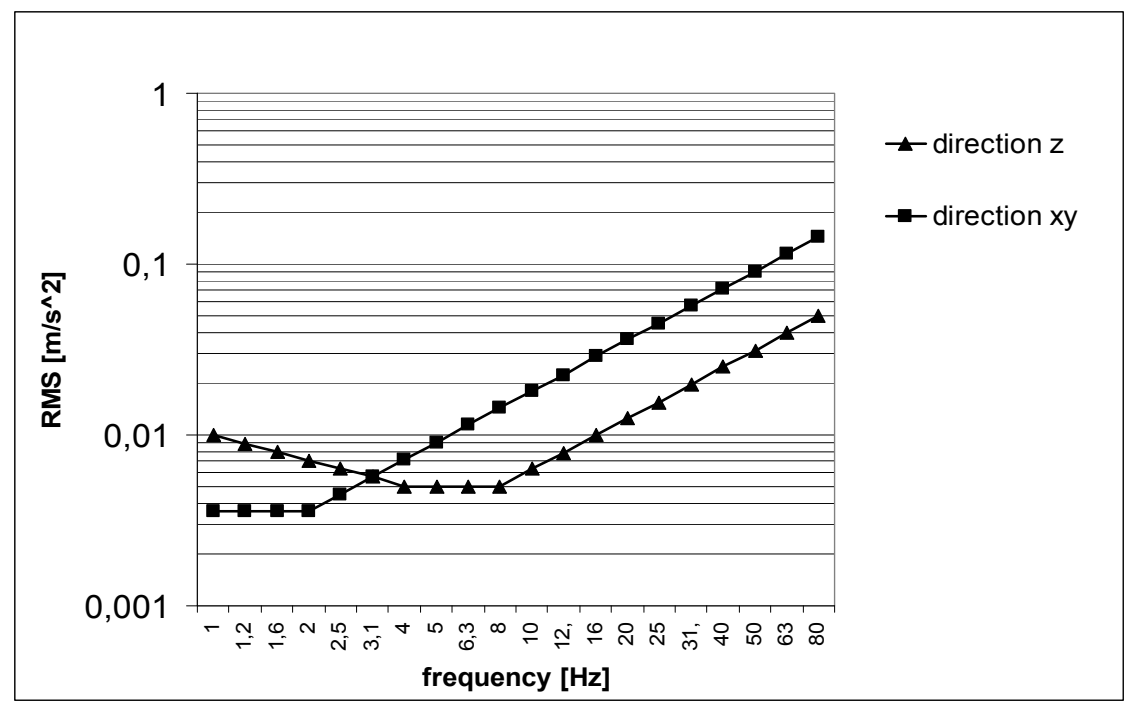

Figure 2: Lines corresponding to the sensation threshold of vibration.

The other factors determining the level of vibration ensuring a man in the building the necessary comforts of vibration (time of vibration occurrence, vibration character, designation of the room) are included in the assessment criterion by adoption of an increasing coefficient " $n$ ". The coefficient " $n$ " increases the coordinates describing the limit of vibration sensation. The result is situation of new lines, parallel to the line of limit of vibration sensation. Vibration with parameter values below this line does not violate the conditions of necessary vibration comfort. Example of characteristics of standards concerning adoption of the coefficient " $n$ " is given [1] in Table 1 .

A similar approach, but including many additional details is given in [5] and recalled here in Table 2. 
Table 1: $\quad$ Value of the factor "n" (see [1]).

\begin{tabular}{|c|c|c|c|}
\hline \multirow[b]{2}{*}{$\begin{array}{l}\text { Designation of the } \\
\text { room }\end{array}$} & \multirow{2}{*}{$\begin{array}{l}\text { Time of } \\
\text { occurring } \\
\text { vibration }\end{array}$} & \multicolumn{2}{|c|}{ The value factor " $n$ " in the occurrence of vibration } \\
\hline & & $\begin{array}{c}\text { steady state (continuous or } \\
\text { intermittent) for more than } 10 \text { times a } \\
\text { day }\end{array}$ & $\begin{array}{l}\text { sporadic, with less } \\
\text { than } 10 \text { times a day }\end{array}$ \\
\hline $\begin{array}{c}\text { Hospitals } \\
\text { (operating-theatres) }\end{array}$ & $\begin{array}{l}\text { Day } \\
\text { Night }\end{array}$ & 1 & 1 \\
\hline \multirow{2}{*}{$\begin{array}{l}\text { Hospitals (rooms of } \\
\text { patients) }\end{array}$} & Day & 2 & 8 \\
\hline & Night & 1 & 4 \\
\hline \multirow{2}{*}{ Residential } & Day & 4 & 32 \\
\hline & Night & 1,4 & 4 \\
\hline Offices & $\begin{array}{l}\text { Day } \\
\text { Night }\end{array}$ & 4 & 64 \\
\hline Workshops & $\begin{array}{l}\text { Day } \\
\text { Night }\end{array}$ & 8 & 128 \\
\hline
\end{tabular}

Table 2: $\quad$ Value of the factor "n" (see [5]).

\begin{tabular}{|c|c|c|c|}
\hline Place & Time & $\begin{array}{l}\text { Continuous of } \\
\text { intermittent } \\
\text { vibration }\end{array}$ & $\begin{array}{l}\text { Transient vibration } \\
\text { excitation with several } \\
\text { occurrences per day }\end{array}$ \\
\hline $\begin{array}{c}\text { Critical working areas } \\
\text { (hospital, operating - } \\
\text { theatres, precision } \\
\text { laboratories) }\end{array}$ & $\begin{array}{c}\text { Day } \\
\text { Night }\end{array}$ & 1 & 1 \\
\hline \multirow{2}{*}{ Residential } & Day & $2 \div 4$ & $30 \div 90$ \\
\hline & Night & 1,4 & $1,4 \div 20$ \\
\hline Office & $\begin{array}{c}\text { Day } \\
\text { Night }\end{array}$ & 4 & $60 \div 128$ \\
\hline Workshop & $\begin{array}{c}\text { Day } \\
\text { Night }\end{array}$ & 8 & $90 \div 128$ \\
\hline \multicolumn{4}{|c|}{$\begin{array}{l}\text { The values given in ranges (from - to) are further described in the standard, } \\
\text { which enables them to clarify, depending on the nature and terms of vibration } \\
\text { reception. }\end{array}$} \\
\hline
\end{tabular}

Based on the above information the criteria for the assessment assigned to a particular diagnostic situation can be determined in detail. 
An example of formulation of specific criteria for vertical vibration of the floor $(Z)$ of a continuous character, taking into account the possibility of occurrence of these vibrations in the daytime (man in the upright position, i.e. with axes $\mathrm{Z}$ and $\mathrm{z}$ overlap) and night (man lying down, i.e. axes $\mathrm{Z}$ and $\mathrm{xy}$ overlap) are given in Fig. 3. The criteria summarized in this diagram relate to people in the residential areas.

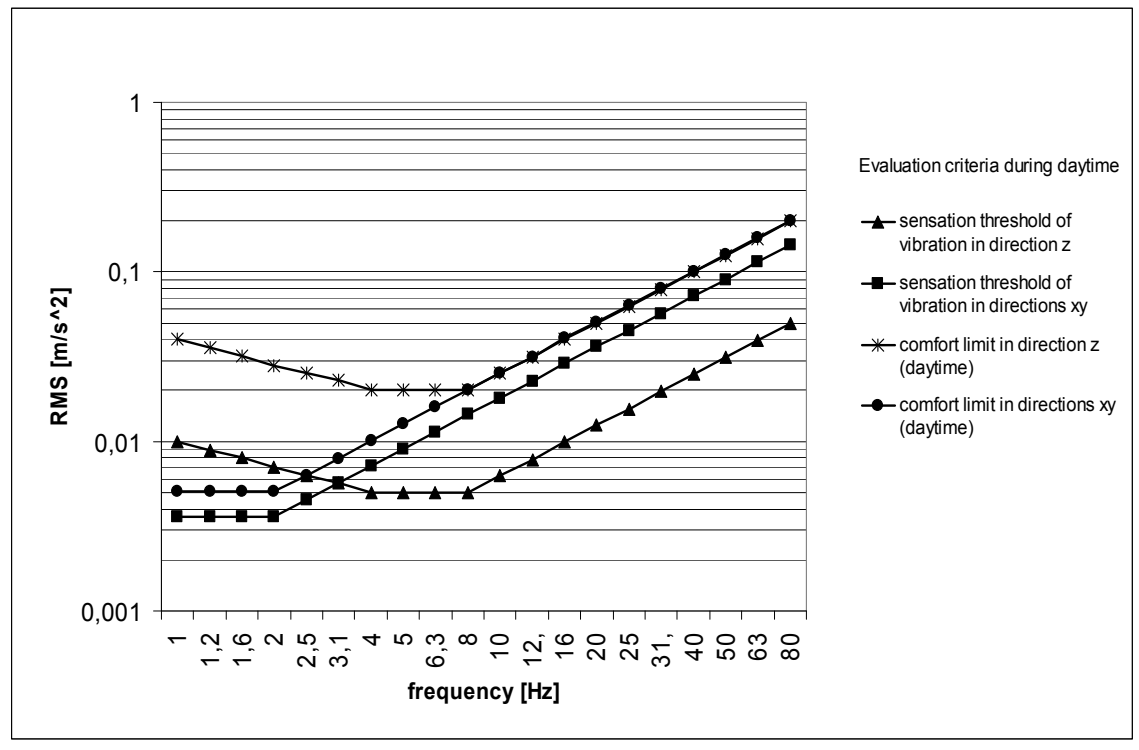

Figure 3: Example of defining of a specific criterion for assessing the influence on people in the residential area of floor vertical vibration in the daytime and nighttime.

Table 3: Criteria for assessing the impact of vibrations depending on the value VDV $\left[\mathrm{m} / \mathrm{s}^{1,75}\right]$.

\begin{tabular}{|c|c|c|c|}
\hline Place & $\begin{array}{c}\text { Low probability of } \\
\text { adverse comments }\end{array}$ & $\begin{array}{c}\text { Adverse comments } \\
\text { possible }\end{array}$ & $\begin{array}{c}\text { Adverse comments } \\
\text { probable }\end{array}$ \\
\hline $\begin{array}{c}\text { Residential } \\
\text { buildings } \\
\text { 16h day }\end{array}$ & $0,2 \div 0,4$ & $0,4 \div 0,8$ & $0,8 \div 1,6$ \\
\hline $\begin{array}{c}\text { Residential } \\
\text { buildings } 8 \mathrm{~h} \\
\text { night }\end{array}$ & 0,13 & 0,26 & 0,51 \\
\hline
\end{tabular}

In a similar way the criteria for assessing the impact of vibration on man are formed, if the vibration dose (standards $[2,3,5]$ ) is used in evaluation of 
vibrations. Table 3 (after [5]) includes the respective quantities constituting the assessment criteria of the influence of vibration on people in buildings, staying in residential areas.

In the standard [3] three levels of demarcation are also introduced and were denoted: $\mathrm{Au}$-vibration sensation threshold, $\mathrm{Ar}$ - medium comfort conditions and Ao - upper limit to ensure the necessary comfort vibration.

\section{Application of evaluation criteria}

Criteria for assessing the influence of vibration on people in buildings can be used in the diagnosis and taken into account in the designing of buildings. Diagnostic assessment occurs when it is possible to perform measurements of vibration directly at the site of their reception by man. Then the record of vibrations in the building measured at the place of receipt by man is presented in a form with corresponding application of assessment criteria applied. The frequency structure of these vibrations in the $1 / 3$ octave bands can therefore be given or a vibration dose can be appointed. For such presentation of measurement results the evaluation criteria are used and on this basis, a diagnosis is formulated.

In the case of a designed building at first a computational model (e.g. FEM model) is elaborated and the predicted kinematic forcing vibration of the building is determinate. In the next stage vibrations of the building in areas of receipt by people (individual floors) are calculated and the vibrograms are analyzed similarly as described above. The procedure for determining an appropriate building computational model is presented e.g. in [13].

It is worth noting that from the two methods of assessing the influence of vibration on people in buildings included in the standards, more information useful in the diagnosis and design is achieved by using the frequency structure of the vibration in $1 / 3$ octave bands as a parameter of assessment. However, in order to make the estimation more precise using this criterion a more precise determination of the value of factor " $n$ " becomes necessary This procedure has already been introduced in the ISO standards (see $[4,5]$ ).

In the case of impulse vibration the range, which houses the factor " $n$ " is relatively wide (see Table 2). For example, with regard to residential areas and occasional vibrations the factor " $\mathrm{n}$ " is recommended to be taken in the range from 30 to 90 . However, the additional information provided in the standards [4, 5] permit to define precisely the value " $n$ " in dependence on: social and cultural conditioning, location of the building (urban or suburban area), frequency, duration, etc.

\section{New directions in research on precising the assessment}

The vibration frequency range in which the assessment is carried out is given in the standards. The analysis concerns vibration in the range from 1 to $80 \mathrm{~Hz}$. Erection of high and very high buildings causes a situation that this range should be extended towards low frequencies (less than 1Hz). Already, the Japanese standard [14] considers the effect of vibration frequency range from 0.1 to $6 \mathrm{~Hz}$. 
The ISO [15] also includes vibration of frequencies from 0.1 to $1 \mathrm{~Hz}$. In the assessment Figure 4 summarizes the information about the proposed criteria for assessing the impact of vibration on people in the buildings listed in the standards $[14,15]$ in relation to records in the standard [5]. The criterion concerns vibrations transmitted to humans along the z-axis (feet - the head) in the residential area during daytime. This statement already shows that it is necessary to conduct further research into information characterizing the effect of vibrations in the low frequency range.

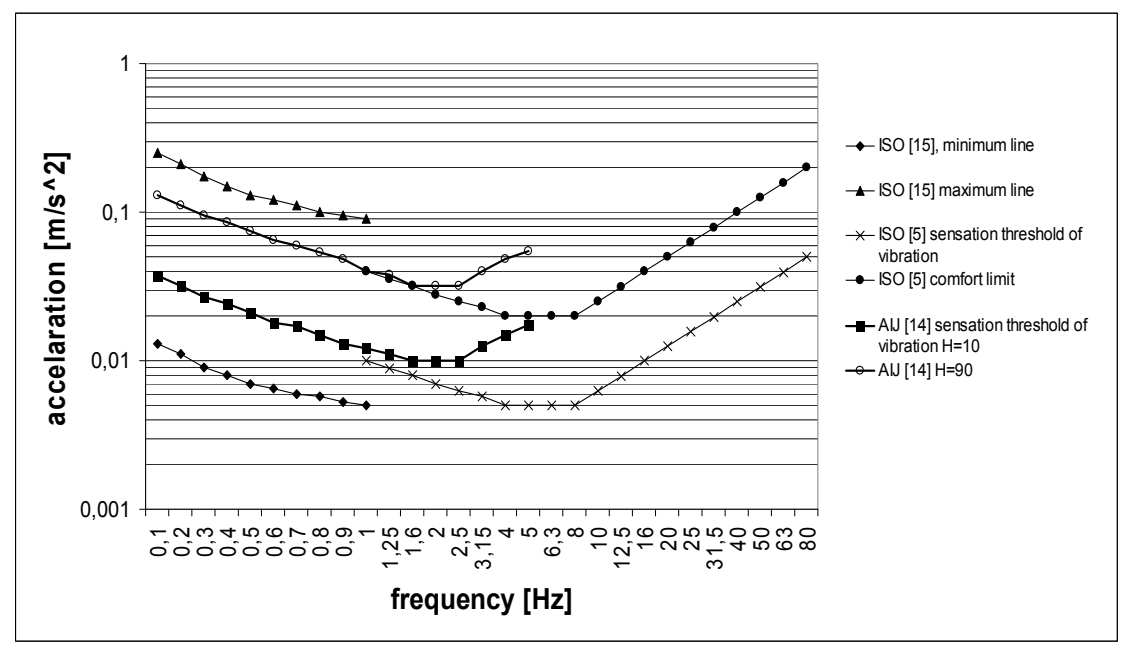

Figure 4: Comparison of criteria for assessing the influence of vibration transmitted to people in the direction feet - hand according to the standards $[5,14,15]$ taking into account very low-frequency.

Increasingly, research is undertaken on the effects of duration of vibrations on vibration reception by man (i.e. exposure to vibration). Mostly this factor is taken into account in assessment carried out by use of the vibration dose. Relatively rarely the frequency spectrum in $1 / 3$ octave band is applied in assessing the influence of vibration.

Investigations are also undertaken on the influence of the shape of motion forms the base on human perception of vibration. In [6] the results of such a research were described. During the experiment horizontal vibrations of the base in various shapes were induced. They were thus generated vibrations: clearly unidirectional (X or $\mathrm{Y}$ ), circular and elliptical, all of different - very low frequencies. The participants of the experiment aimed at identification of the shapes of realized vibrations. The results of the identification are given on Fig.5. It can be seen that the participants identified almost univocally vibration of evidently one direction and vibration moving a circular line. In the case of vibration of elliptical motion, this identification was not so univocal. 
364 Ravage of the Planet III

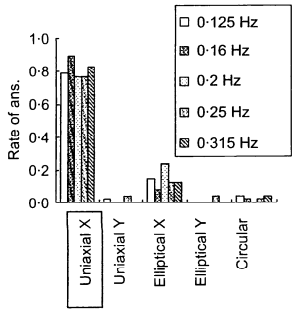

(a)

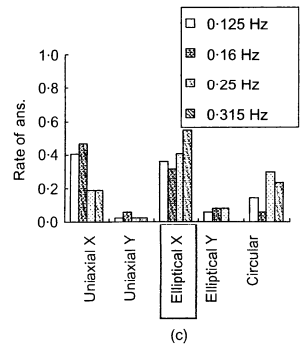

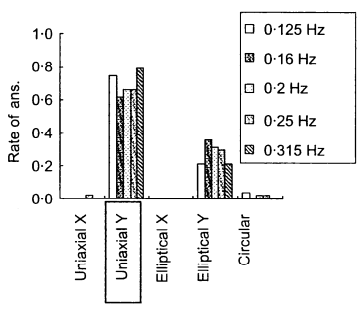

(b)

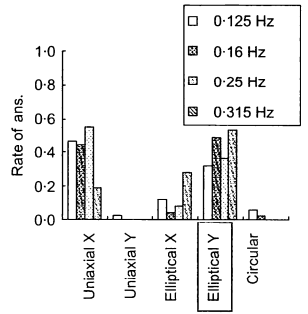

(d)

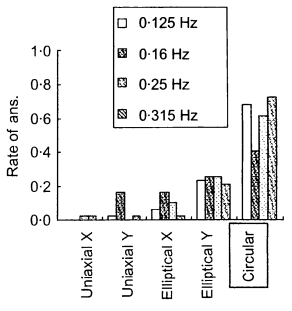

(e)

Figure 5: Results of an experiment on identification of shapes of horizontal vibration by men (see [6]).

Equally interesting were the results of experiments in which perception by man of harmonic vibration and vibration of a random character was checked. The results of these tests are given in Fig. 6.

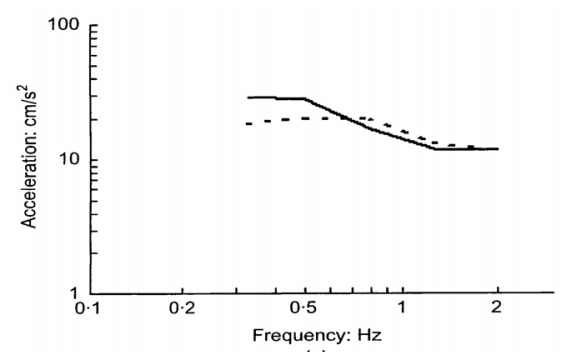

(a)

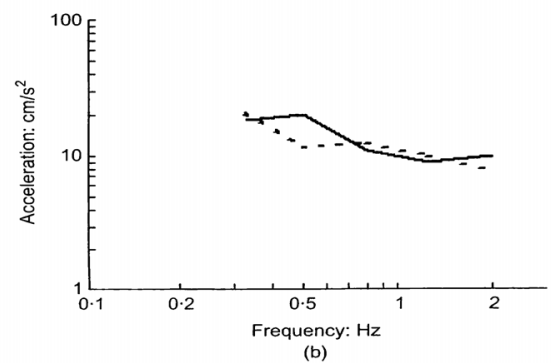

Figure 6: Perception by people of random vibration (continuous) and harmonic vibration (dashed line) - as [6]. 
It turns out that in the frequency range from 0.3 to $0.6 \mathrm{~Hz}$ harmonic vibration is felt at a lower vibration amplitude than vibration of random character. This means that the actual line of the vibration sensation threshold of harmonic vibrations in the considered frequency range lies lower than that of the corresponding line of random vibration.

\section{Conclusions}

Problems of assessing the impact of vibration on people in buildings are more and more frequently the subject of dynamical diagnoses. Hence it became necessary to define assessing criteria. By introducing these criteria into the standards their unification becomes possible. Increasingly, the requirements imposed the protection of the human environment increase the interest in such evaluation also concerning impact vibration. In particular, it is a question of vibration generated by vehicles, i.e. transport vibrations. The intensity of these vibrations is growing.

A comparison of evaluation criteria introduced into the international and national standards shows similarity of records. Currently are two groups of evaluation criteria used and improved. In one of these the criteria are stored using the frequency structure in 1/3 octave bands, while in the other one - by the so called, vibration dose. As shown above, the first of these methods contains more information which may be helpful in diagnosis and in designing new buildings and their effective vibration insulation (comp. [16]). At present research is carried out on increasing the precision of the guidelines relating to the two groups of criteria. In particular, it concerns a range of vibration frequencies below $1 \mathrm{~Hz}$ and a more precise determination of the value of the factor " $n$ " in relation to impulse and occasional vibrations.

\section{Acknowledgements}

Scientific research has been carried out as a part of the Project "Innovative recourses and effective methods of safety improvement and durability of buildings and transport infrastructure in the sustainable development" financed by the European Union from the European Fund of Regional Development based on the Operational Program of the Innovative Economy.

\section{References}

[1] PN-88/B-02171, Evaluation of vibrations influence on people in buildings, 1988, Polish Standard (in Polish).

[2] BS 6472-1:2008, Guide to evaluation of human exposure to vibration in buildings, Part 1: Vibration sources other than blasting, 2008, British Standard.

[3] DIN 4150-2, Structural vibration, Part 2: Human exposure to vibration in buildings, 1999, German Standard. 
[4] ISO 2631-2, Guide to the evaluation of human exposure to whole body vibration. Part 2- Vibration in buildings, 2003, International Organization for Standardization.

[5] ISO 10137 Bases for design of structures - Serviceability of buildings and walkways against vibration, 2007, International Organization for Standardization.

[6] Tamura Y., Kawana S., Nakamura O., Kanda J. \& Nakatà S., Evaluation perception of wind-induced vibration in buildings. Structures \& Buildings, 159, pp. 1-11, 2006.

[7] Blume J., Motion perception in the low-frequency range. Contract report AT(26-1)-99. US Atomic Energy Commission, Nevada Operations Office. July 1969.

[8] Benson A.J., Diaz E. \& Farrugia P.: The perception of body orientation relative to a rotating linear acceleration vector. Fortschr. zool., 23, pp. 264-274, 1975.

[9] Goto T., Studies on wind-induced motion of tall buildings based on occupant's reactions. Journal of Wind Engineering and Industrial Aerodynamics, 13, pp. 241-252, 1983.

[10] Jeary A. P., Morris R. G. \& Tomlinson R. W., Perception of vibration-tests in tall buildings. Journal of Wind Engineering and Industrial Aerodynamics, 28, pp. 361-370, 1988.

[11] Hansen R. T., Read J. W. \& Vanmarcke E. H., Human response to windinduced motion of buildings. Proc. ASCE, ST7, 1973.

[12] Reed J. W., Wind-induced motion and human discomfort in tall buildings. Massachusetts Institute of technology, 1971.

[13] Kawecki J., Stypuła K.: Methods of determination of a building model useful in evaluation of paraseismic vibration effect on people; Technical Journal, Cracow University of Technology, 2-B, pp. 39-6, 2007 (in Polish).

[14] AIJ-GEH-2004. Guidelines for the evaluation of habitability to building vibration, 2007, Architectural Institute of Japan.

[15] ISO 6897: Guidelines for the evaluation of the response of occupants of fixed structures, especially buildings and off-shore structures, to lowfrequency horizontal motion (0,063 to $1 \mathrm{~Hz})$, 1984, International Organization for Standardization.

[16] Kawecki J., Kozioł K., Stypuła K.: Influence of metro tunnel structure on prognosed vibrations received by people staying in nearly building; Technical Journal, Cracow University of Technology, 3-B(11), pp. 51-58, 2010 (in Polish). 